NICE, 2004.

2. Cartagena Farias J, Porter L, McManus S, et al. Prescribing patterns in dependence forming medicines. London: NatCen, 2017.

DOI: https://doi.org/10.3399/bjgp17X693257

\section{NHS is not all that bad}

The NHS comes in for a lot of complaints. But my parents are in their late 80 s and in the last 6 months my father has had a series of procedures to remove small spots of cancer on his skin, had cataracts removed from both eyes, and had his blood pressure 'fixed'. My mother suffers from severe joint pain, colitis, and a challenging memory issue. Her GP is the nearest thing to a saint one could hope to have care for your mother.

I now live in the US and am fortunate to be able to afford any care I need. But I see people every day who suffer from things that go untreated in the US that would be treated in a moment if the patient was in the UK.

Is the NHS perfect? No. But let's not forget to recognise the enormous amount of good it does every day.
Martyn Hills,

E-mail: martyn.hills@gmail.com

\section{REFERENCE}

1. Jones R. Deconstructing the doctor. $\mathrm{Br} \mathrm{J}$ Gen Pract 2017; DOI: https://doi.org/10.3399/ bjgp17X692177.

DOI: https://doi.org/10.3399/bjgp17X693269

\section{Pharmacists' role in primary care}

I enjoyed reading Butterworth et als article in the BJGP. I I am a retired GP who has worked closely with local pharmacists, valuing their opinions and knowledge. We included an independent pharmacy in a new-build multidisciplinary primary care centre in Norwich back in the 1990s. The forward-looking local NHS administration (then the FPC) paid the pharmacist to have an extended role with our practice. He not only worked closely with us, checking the accuracy of prescriptions and raising any queries, but he also systematically reviewed all our repeat prescribing and, for instance, he converted all drugs, group by group, to generic where possible. And he took the time to work with patients explaining the changes, sometimes having to assure people of the safety and equivalence of a new pack.

The advantages were immeasurable. We doctors were helped to be much more aware of our prescribing in general, and of course the pharmacist saved the NHS drug bill much more than the scheme cost the FPC. Our patients were happy with the improved service. I'm sad that this kind of relationship has not become more universal.

Robert MacGibbon,

\section{GP (retired).}

E-mail: rmacgibbonabtinternet.com

\section{REFERENCE}

1. Butterworth J, Sansom A, Sims L, et al. Pharmacists' perceptions of their emerging general practice roles in UK primary care: a qualitative interview study. Br J Gen Pract 2017; DOI: https://doi.org/10.3399/ bjgp17X691733.

DOI: https://doi.org/10.3399/bjgp17X69328 